\title{
The influence of efficiency of the cooling system on the thermodynamic parameters and performance of a two - stage VC 20.96 reciprocating compressor designed to serve as a marine engine starter
}

\author{
Mateusz Grzelczak, Ph.D., \\ Poznan University of Technology, Poland
}

\begin{abstract}

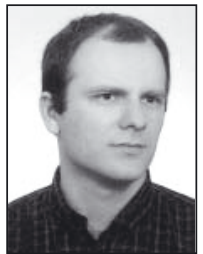

The paper presents results of the research related to the analysis of the thermodynamic and flow processes occurring in a prototype VC 20.96 two-stage liquid-cooled reciprocating compressor. The compressor has been developed and manufactured by H. Cegielski Poznan metal works in collaboration with the Poznan University of Technology. The research related to the VC compressor was realized within the KBN 3127/C.T07-6/2002 project titled "Development of design of type-series of reciprocating compressors and their implementation in production". The basic task of the project was to develop two type-series of liquid-and air-cooled reciprocating compressors of the $V$-and $W$-arrangement, designed to serve as marine engine starters. The result of the design work was the manufacturing of two compressors: the VC 20.96 liquid-cooled compressor and the WP 18.80 air-cooled one. The main aim of the research described in this paper was to evaluate the efficiency of the cooling system which uses inter-coolers integrated with the compressing stages and the cooperation of the compressing stages in terms of pressure ratio distribution. Owing to the cooling method, the applied design assumptions enabled to develop a compact compressor fulfilling the assumed operating parameters.
\end{abstract}

Key words: reciprocating compressor; liquid-cooled compressor; efficiency; polytropic exponent

\section{INTRODUCTION}

The requirements set for the compressing machines installed in marine engine rooms force the designers to develop simple and reliable design solutions with particular focus on their limited size. Additionally, low electrical energy consumption and low coolant flow per unit of compressed gas are required from the compressing units.

In light of the above given conditions the engineers aimed at ensuring the assumed parameters such as pressure increments and volumetric flow rates of the compressed gas, thus guaranteeing high efficiency of the process through the improvement of the cooling.

In the $\mathrm{VC}$ compressor has been implemented a solution that consists in integrating the inter-cooler and the after-cooler with the compressing stages. This required developing complex casts of the cylinder heads and coolers.

The applied uneven distribution of pressure ratio between the first and the second stage contributed to the development of excessively high temperatures in the second stage compression chamber. Another problem yet occurred - the air in the second stage suction chamber heated up. Hence, the main task described in the paper was the analysis of the inter-cooling system and the cooling of the cylinder walls, based on the measurements of the thermodynamic parameters and pressures in function of crankshaft angle for each of the compressing stages. The obtained indicator diagrams enabled to verify the efficiency of the cooling of the cylinder walls, based on the determined polytropic exponents of the compression process. Prior to modifying the design that consisted in development of a new compressing stage of the piston diameter of $86 \mathrm{~mm}$, tests were performed for three values of the clearance volume of the second stage. The tests were aimed at determining the minimum amount of coolant fulfilling the condition of similar temperature values at the end of compression in each of the stages.

\section{TECHNICAL SPECIFICATION OF THE COMPRESSOR}

The VC20.96 liquid-cooled compressor reaches the discharge pressure of $\mathrm{P}_{\mathrm{t}}=30$ bar at the flow rate $\mathrm{q}_{\mathrm{v}}=220 \mathrm{~m}^{3} / \mathrm{h}$ and the compressor speed $\mathrm{N}=1800 \mathrm{rpm}$. Below in Tab. 1 are shown the basic geometrical and operating parameters obtained from the design calculations. 
Tab. 1. VC20.96 compressor design specification

\begin{tabular}{|c|c|c|c|c|c|c|}
\hline \multirow{2}{*}{ No. } & \multirow{2}{*}{ Quantity } & \multirow{2}{*}{ Unit } & \multicolumn{4}{|c|}{ Compressor crankshaft speed $\mathbf{N}$ [rpm] } \\
\hline & & & 1000 & 1200 & 1500 & 1800 \\
\hline 1. & $\begin{array}{l}\text { Air suction parameters: } \\
\text { - pressure } \mathrm{p}_{\mathrm{o}} \\
\text { - temperature } \mathrm{t}_{\mathrm{o}} \\
\text { - relative humidity } \varphi \\
\end{array}$ & $\begin{array}{l}\text { bar } \\
{ }^{\circ} \mathrm{C} \\
\%\end{array}$ & $\begin{array}{l}1.0 \\
20 \div 45 \\
10.0 \div 95.0\end{array}$ & & & \\
\hline 2. & $\begin{array}{l}\text { Air compression parameters: } \\
\text { - nominal discharge pressure } p_{D} \\
\text { - maximum temperature } t_{D, \max }\end{array}$ & $\begin{array}{l}\text { bar } \\
{ }^{\circ} \mathrm{C}\end{array}$ & \multicolumn{2}{|l|}{$\begin{array}{l}30 \\
90\end{array}$} & & \\
\hline 3. & $\begin{array}{l}\text { Air volumetric flow rate } \mathrm{q}_{\mathrm{v}} \text { for } \\
\text { the nominal discharge pressure } \\
\mathrm{p}_{\mathrm{D}}=30 \text { bar and ambient parameters: } \\
-\mathrm{t}_{\mathrm{o}}=20^{\circ} \mathrm{C}, \varphi=50.0 \% \\
-\mathrm{t}_{\mathrm{o}}=45^{\circ} \mathrm{C}, \varphi=50.0 \% \\
\end{array}$ & $\begin{array}{l}\mathrm{m}^{3} / \mathrm{h} \\
\mathrm{m}^{3} / \mathrm{h}\end{array}$ & $\begin{array}{l}128 \\
105 \\
\end{array}$ & $\begin{array}{l}154 \\
126 \\
\end{array}$ & $\begin{array}{l}192 \\
158 \\
\end{array}$ & $\begin{array}{l}229 \\
189 \\
\end{array}$ \\
\hline 4. & $\begin{array}{l}\text { Design parameters: } \\
\text { - cylinder bore of } 1 \text { st stage, } D_{1} \\
\text { - cylinder bore of } 2^{\text {nd }} \text { stage, } D_{2} \\
\text { - piston stroke } \mathrm{s} \\
\text { - clearance volume of } 1^{\text {st }} \text { stage, } V_{C, 1} \\
\text { - clearance volume of } 2^{\text {nd }} \text { stage, }, V_{C, 2} \\
\text { - length of the connecting rod, } 1_{1,2}\end{array}$ & $\begin{array}{c}\mathrm{mm} \\
\mathrm{mm} \\
\mathrm{mm} \\
\mathrm{m}^{3} \\
\mathrm{~m}^{3} \\
\mathrm{~mm}\end{array}$ & \multicolumn{4}{|c|}{$\begin{array}{l}200 \\
90 \\
96 \\
0^{-4} \div 2.5110^{-4} \\
0^{-5} \div 3.58 \quad 10^{-5} \\
284\end{array}$} \\
\hline 5. & $\begin{array}{l}\text { Pressure ratio of } 1^{\text {st }} \text { stage, } \varepsilon_{1} \text {, for the } \\
\text { ambient parameters: } \\
-\mathrm{t}_{\mathrm{o}}=20^{\circ} \mathrm{C}, \varphi=0.0 \% \\
-\mathrm{t}_{\mathrm{o}}=45^{\circ} \mathrm{C}, \varphi=50.0 \%\end{array}$ & - & $\begin{array}{l}5.34 \\
5.28\end{array}$ & $\begin{array}{l}5.36 \\
5.31\end{array}$ & $\begin{array}{l}5.38 \\
5.37\end{array}$ & $\begin{array}{l}5.41 \\
5.40\end{array}$ \\
\hline \multirow[t]{2}{*}{6.} & $\begin{array}{l}\text { Cooling water: } \\
\text { - temperature at inlet } \mathrm{t}_{\mathrm{w}}\end{array}$ & ${ }^{\circ} \mathrm{C}$ & \multicolumn{4}{|c|}{$15 \div 40$} \\
\hline & - volumetric flow rate $\mathrm{q}_{\mathrm{vw}}$ & $1 / \mathrm{min}$ & 140 & 115 & 95 & 75 \\
\hline
\end{tabular}

Fig. 1 presents the image of the prototype $\mathrm{VC}$ compressor manufactured by H. Cegielski Poznan S.A.

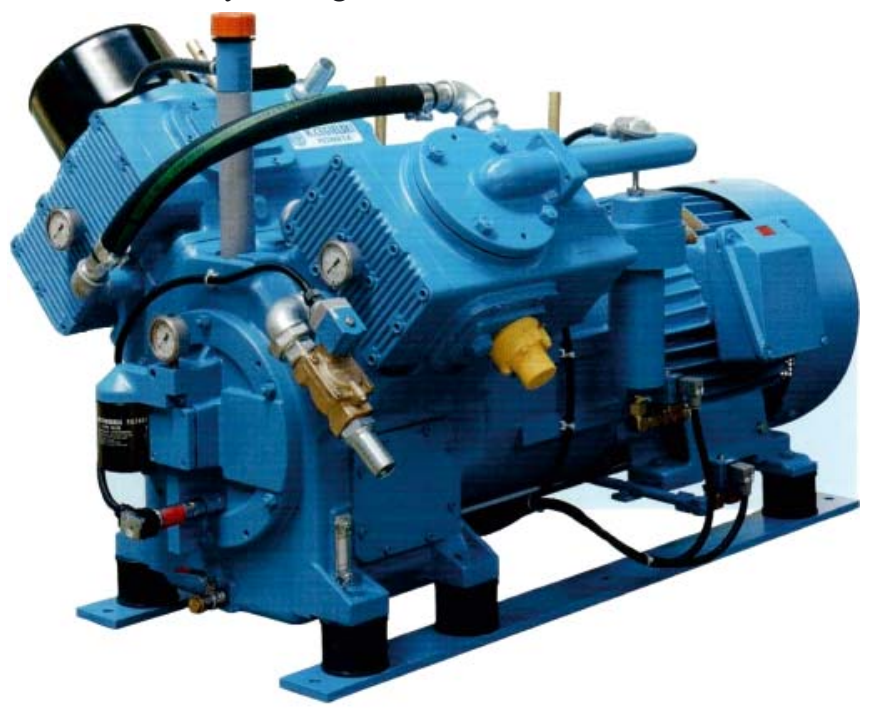

Fig. 1. The prototype VC 20.96 reciprocating compressor

\section{THE SCOPE OF THE RESEARCH AND THE TEST STAND}

The research program comprised the thermodynamic, flow, dynamic and acoustic measurements.

The basis for the performance of the research was the work titled 'The program of trials of the prototype of the VC20.96 compressor' and the PN-ISO 1217:1999 and PN-93/M53950/01 standards.

The above mentioned standards are related to acceptance tests carried out on positive displacement compressors, i.e mainly to determining the efficiency and power at a given pressure during compression. The scope of the tests on the VC20.96 compressor has been thus extended in relation to this standard. Additionally, the standard related to the vibration and noise measurements (PN-84/N-01330) has been applied.

The trials covered the compression process in the individual compression stages and the whole compressor, as well as the cooling process (inter-cooling and after-cooling).

The tests were carried out for the ambient conditions close to normal: $\mathrm{p}_{\mathrm{o}}=1 \mathrm{bar}, \mathrm{t}_{\mathrm{o}}=20^{\circ} \mathrm{C}$, and the relative humidity $\varphi=60 \%$, and also for the tropical conditions, i.e. the ambient temperature $\mathrm{t}_{\mathrm{o}}=45^{\circ} \mathrm{C}$.

The trials were performed for varying cooling rates in a wide range of cooling-water flow and a full range of pressures during compression: $5,10,15,20,25$ and 30 bar for four crankshaft speeds: $1000,1200,1500$ and $1800 \mathrm{rpm}$.

The tests were divided into two stages [phases]. In the first stage phase the basic quantities were measured such as discharge pressure, volumetric flow rate and power at assumed speeds. The second stage phase was related to the pressure and temperature measurements in the suction and compression chambers of each of the compression stages, the measurements of the hydraulic resistance in the form of pressure drops and the measurement of temperatures upstream and downstream the coolers and the mass of the condensed liquid downstream the coolers. 


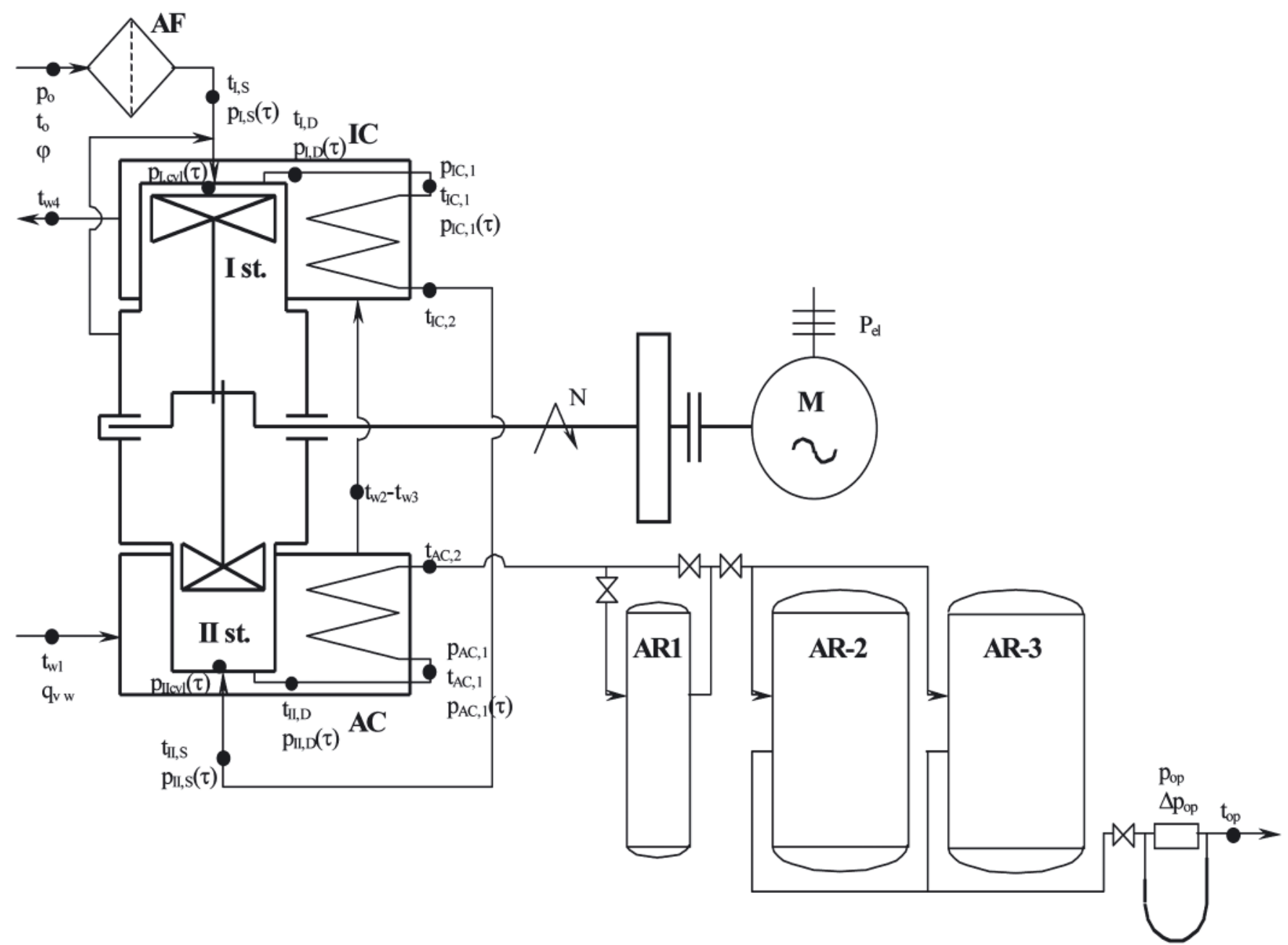

Fig. 2. Schematic diagram of the research stand for measuring stationary thermodynamic and mechanical parameters and the runs of pressure in function of crankshaft angle

Within the thermodynamic and flow investigations of the compressor the runs of pressure in function of crankshaft angle were measured in order to obtain the indicator diagrams of the compression process. The runs of pressure were measured inside the cylinders and in selected cross sections of the air ducts of the first and second stages of the compressor for the following operating conditions: discharge pressure of 15 and $30 \mathrm{bar}$, crankshaft speed of 1500 and $1800 \mathrm{rpm}$. The tests were extended by the measurements of the runs of pressure for two diameters of cylinder bore of the second stage: $d_{I}=90 \mathrm{~mm}$ and $\mathrm{d}_{\mathrm{II}}=86 \mathrm{~mm}$.

The measurement of the runs of pressure in function of crankshaft angle was realized by using two ENDEVCO 8540 piezoresistive pressure transducers (differing in the measurement range). The pressure measurement in the first stage was carried out with the transducer operating in the range of $0 \div 689.5 \mathrm{kPa}$ of the absolute pressure, and in the second stage with the transducer operating in the range of $0 \div 3447.4$ $\mathrm{kPa}$ of the absolute pressure.

The above mentioned pressure converters have a calibration certificate issued by National Institute of Standards and Technology (NIST) USA and accordance with MIL-STD45662A (MILITARY STANDARD - Calibration Systems Requirements).

The measurement of the values varying in time was realized according to the schematic diagram presented in Fig. 3. The electrical signal from the pressure transducers and the voltage signal from the photoelectric probe designed to measure the crankshaft angle,were converted into a digital signal in the Iotech ADC 488/8SA converter. The signal was converted through an amplifier also operating as a ENDEVCO 136 charger. The $\mathrm{A} / \mathrm{C}$ converter used in the measurements also recorded each of the three measured quantities with the frequency of $\mathrm{f}=20 \mathrm{kHz}$. The digital signal obtained through the internal controller card was saved on a PC.

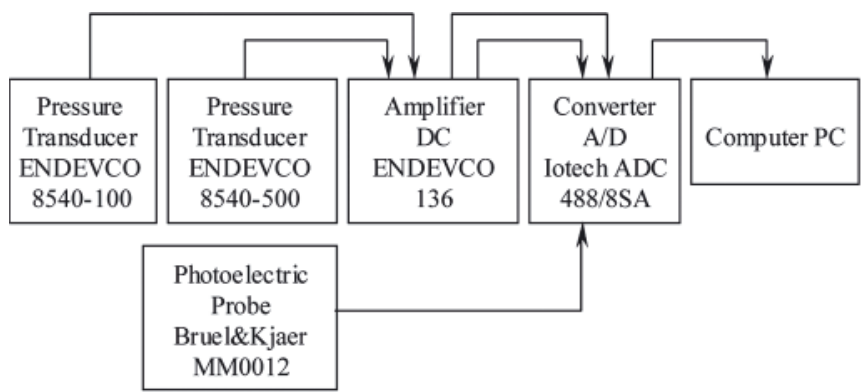

Fig. 3. Schematic diagram of the measurement track for recording the values in function of crankshaft angle

\section{EXPERIMENTAL RESULTS}

The division of the VC compressor research into two stages phases enabled an independent interpretation of the physical quantities which describe the issue of heat exchange in the coolers and through the cylinder walls of each of the compressing stages. The first stage phase of the research consisted in the measurement of the stationary parameters such as temperatures, pressures, volumetric flow rate of air and coolant in the characteristic control cross-sections of the 
reciprocating compressor. The parameters enabled to make an analysis of the efficiency of the inter-cooler and aftercooler. The second stage phase of the research included the measurements of the pressures inside the cylinder in function of crankshaft angle, on the basis of which the $\mathrm{p}-\mathrm{V}$ diagrams have been developed. The obtained pressure runs allowed to evaluate the flow of heat transferred through the cylinder walls from the compressed gas to the coolant. The evaluation has been carried out based on the comparison of the obtained values of the polytropic exponents of the compression and expansion processes for each of the stages.

In the first place, the paper presents the results of the measurements such as characteristics of the discharge pressure in function of the volumetric flow rate of air at the suction (Fig. 4). The obtained results have been presented for four crankshaft speeds. From comparison of the measured volumetric flow rate with the design values it turns out that the chosen assumptions have been satisfied except the crankshaft speed of $\mathrm{N}=1200 \mathrm{rpm}$. The relative difference between the design volumetric flow rate and the measured one for that speed is $12 \%$. In the case of tropical conditions the situation is more advantageous as the design assumptions related to the volumetric flow rate have been fulfilled for the whole range of speeds.

The characteristics of the discharge pressure presented in Fig. 4 in function of the air volumetric flow rate show the specificity of the positive displacement machine for which a drop of the volumetric flow rate occurs as the discharge pressure grows. It has been observed that it is a result of a leakage between the piston and cylinder wall or a leakage in the discharge valves. A relative difference of the volumetric flow rate for a compressor producing the extreme value of pressure at discharge, $\mathrm{p}_{\mathrm{D}}=0.5$ and $3.0 \mathrm{MPa}$, is equal to maximum $15 \%$.

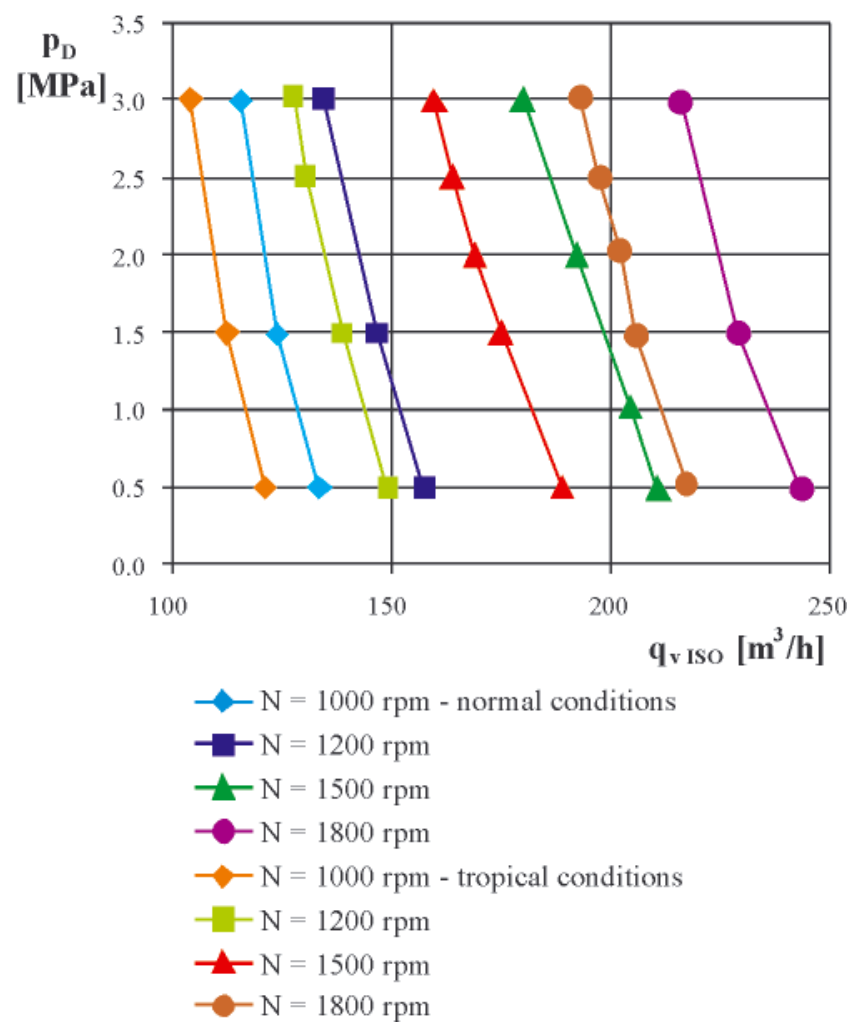

Fig. 4. Characteristics of the compressor discharge pressure in function of the volumetric flow rate for four crankshaft speeds and both the nominal and tropical conditions taken into account

Prior to interpretation of the results (efficiency of the coolers) the values of the discharge temperature and pressure ratios of each of the stages were compared (Fig. 5 and 6). The comparison takes into account the run of the above mentioned parameters in function of the discharge pressure for two volumetric flow rates of the cooling water. The first flow rate was $\mathrm{q}_{\mathrm{v} 1, \mathrm{w}}=30 \mathrm{l} / \mathrm{min}$ and corresponded to the minimum amount of cooling water and the second value of the flow rate was three times greater and amounted to $\mathrm{q}_{\mathrm{v} 1, \mathrm{w}}=90 \mathrm{l} / \mathrm{min}$.

In the case of the run of temperature shown in Fig. 5, can be observed a greater temperature drop as the cooling water flow rate increases in the second compressing stage in comparison to the first stage. This results from a lower temperature of the cooling water supplied to the inter-cooler of the first stage, which consequently contributes to the obtaining of a lower temperature of air downstream the inter-cooler as well as in the suction chamber of the second stage. Additionally, the lower temperature values at the end of the compression process result from the increased heat transfer through the cylinder walls to the coolant.

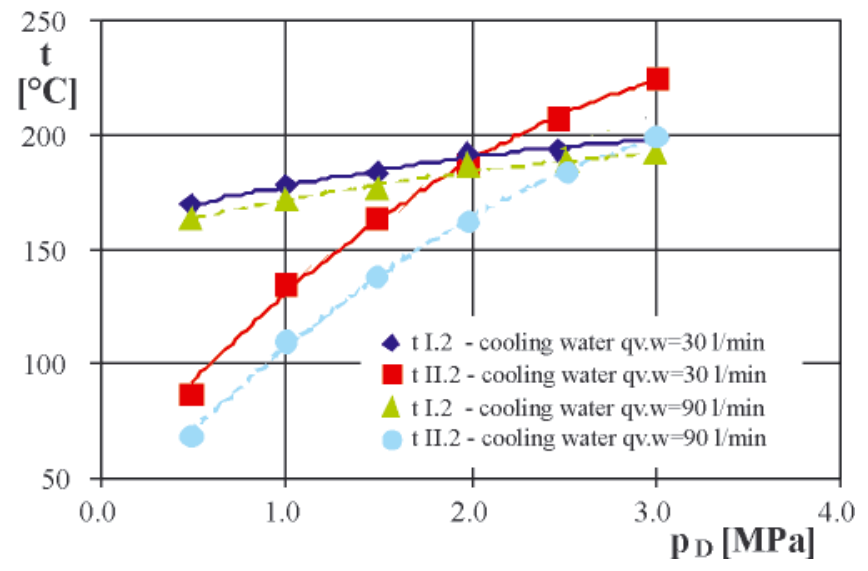

Fig. 5. Comparison of the air temperature runs in the discharge chambers of the first and second stages for the volumetric flow rate of the cooling water $q v, w=30$ and $90 \mathrm{l} / \mathrm{min}$, at the maintained values of $t_{o t}=15^{\circ} \mathrm{C}$ and $N=1500 \mathrm{rpm}$

Another parameter that changed its value due to the increase of the cooling water flow rate is the pressure ratio. More advantageous cooling conditions of the second stage resulted in the increase of the pressure ratio in this stage and a drop of the pressure ratio in the first stage (Fig. 6). This results from the increase of the heat-up volumetric coefficient of the second stage the consequence of which was the distribution of the pressure ratios.

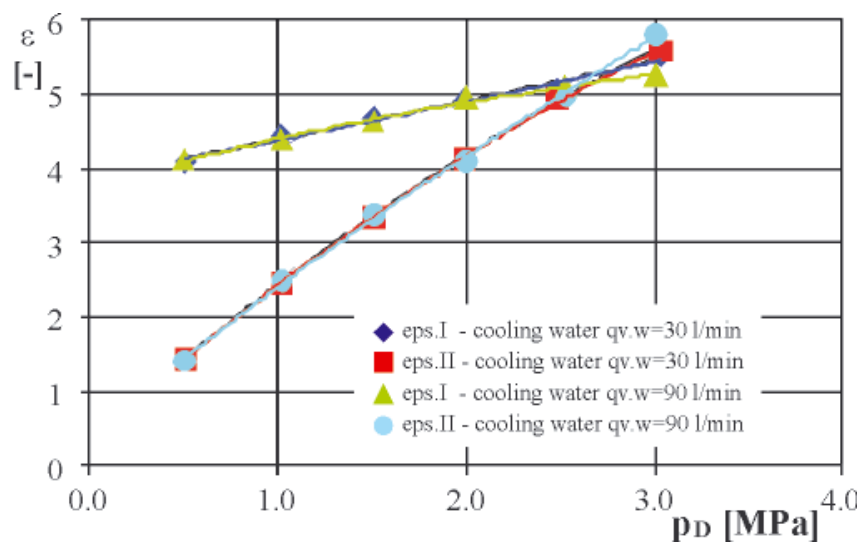

Fig. 6. The comparison of pressure ratios of the first and second stages in function of pressure for the cooling water flow qv,w $=30$ and $90 \mathrm{l} / \mathrm{min}$, at the maintained values of $t_{o}=15^{\circ} \mathrm{C}$ and $N=1500 \mathrm{rpm}$

Based on the obtained measurement results in the form of temperatures of the compressed air and cooling water in the inlet and outlet cross-sections of the inter-cooler and the aftercooler, the values of efficiency of the coolers were determined. 
Below the values of the efficiency of the coolers have been shown for two volumetric flow rates of the cooling water: $\mathrm{q}_{\mathrm{v} 1, \mathrm{w}}=30 \mathrm{l} / \mathrm{min}$ and $\mathrm{q}_{\mathrm{v} 2, \mathrm{w}}=90 \mathrm{l} / \mathrm{min}$. For the calculations, the definition of the efficiency of the heat exchanger operating in the cross current configuration has been selected. This has been chosen because, despite the fact that the inflow of the coolant fulfilled the cross-flow condition, in the majority of the volume of the coolers a cross-current flow was realized. The dependence on the basis of which the efficiency was determined, is as follows:

$$
\mathrm{E}_{\mathrm{IC}}=\frac{\mathrm{T}_{\mathrm{IC}, 1}-\mathrm{T}_{\mathrm{IC}, 2}}{\mathrm{~T}_{\mathrm{IC}, 1}-\mathrm{T}_{\mathrm{w} 3}} \quad \mathrm{E}_{\mathrm{AC}}=\frac{\mathrm{T}_{\mathrm{AC}, 1}-\mathrm{T}_{\mathrm{AC}, 2}}{\mathrm{~T}_{\mathrm{AC}, 1}-\mathrm{T}_{\mathrm{w} 1}}
$$

The efficiency of the inter-cooler for the cooling water flow rate $\mathrm{q}_{\mathrm{v} 1, \mathrm{w}}=30 \mathrm{l} / \mathrm{min}$ and $\mathrm{q}_{\mathrm{v} 2, \mathrm{w}}=90 \mathrm{l} / \mathrm{min}$ is, respectively:

$$
\mathrm{E}_{\mathrm{IC}, \mathrm{n}, 30}=0.88 \quad \mathrm{E}_{\mathrm{IC}, \mathrm{n}, 90}=0.91
$$

The efficiency of the after-cooler for the same water flow rates is:

$$
\mathrm{E}_{\mathrm{AC}, \mathrm{n}, 30}=0.77 \quad \mathrm{E}_{\mathrm{AC}, \mathrm{n}, 90}=0.82
$$

As a complement, based on the obtained measurement results, the values of the efficiency of the inter-cooler and after-cooler have been presented for tropical conditions at the maintained value of the cooling water flow rate $\mathrm{q}_{\mathrm{v}, \mathrm{w}}=140$ $1 / \mathrm{min}$.

The efficiency of the inter-cooler is:

$$
\mathrm{E}_{\mathrm{IC}, \mathrm{t}, 140}=0.92
$$

The efficiency of the aftercooler is:

$$
\mathrm{E}_{\mathrm{AC}, \mathrm{t}, 140}=0.87
$$

The uneven distribution of the pressure ratio assumed at the design stage led to an excess of the admissible temperature for the second stage of the compressor. For this reason the interpretation of the results took a form of discharge temperatures, values of the pressure ratios, air volumetric flow rate and electrical power of the compressor in the whole range of the volumetric flow rate of the cooling water. The complement of the analysis was the inclusion of three values of clearance volume for the second stage. The assumed strategy aimed at selecting a new diameter of the second-stage cylinder that would allow a distribution of pressure ratios so that the admissible discharge temperature is not exceeded at maintaining the minimum possible value of the volumetric flow rate of the cooling water, in the same time.

Fig. $7 \div 9$ present the above mentioned thermodynamic parameters for the designed value of the clearance volume marked $\mathrm{V}_{\mathrm{C}}$ on the graphs and two outstanding volumes extended by $50 \%$ and $100 \%$ as compared to the design value $\left(\mathrm{V}_{\mathrm{Cl}}=\mathrm{V}_{\mathrm{C}}\right.$, $\mathrm{V}_{\mathrm{C} 2}=1,5 \mathrm{~V}_{\mathrm{C}}$ and $\mathrm{V}_{\mathrm{C} 3}=2,0 \mathrm{~V}_{\mathrm{C}}$ ). The developed measurement results prove that the distribution of the pressure ratios obtained for the lowest clearance volume fulfills the design assumptions (Fig. 8.). The average value of the pressure ratio for the first stage was $\varepsilon_{\mathrm{I}}=4.9$, and, the pressure ratio of the second stage is greater and amounts to $\varepsilon_{\mathrm{II}}=6.3$. An uneven distribution of the pressure ratios and the excess temperature in the suction chamber of the second stage have led to an excess of the admissible air temperature $\left(\mathrm{t}_{\max }=230^{\circ} \mathrm{C}\right.$ ) (which may reduce compressor mechanical durability and worsen oil lubricating properties). Based on the performed measurements for the design clearance volume, the temperature of the second stage was on the admissible level but the discharge temperature of the first stage at the volumetric water flow rate $\mathrm{q}_{\mathrm{v}, \mathrm{w}}=60 \mathrm{l} / \mathrm{min}$ was lower by $\Delta \mathrm{t} 38^{\circ} \mathrm{C}$ (Fig. 7). Unfortunately, approximating lower values of the volumetric cooling water flow rate would clearly lead to the excess of the admissible temperature of the first stage. As a complement, the value of the electrical power being the highest due to the compressed air flow rate reaching $\mathrm{q}_{\mathrm{v}, \mathrm{w}}=180 \mathrm{~m}^{3} / \mathrm{h}$, has been presented in Fig. 9. This results from the maintaining of the highest value of the volumetric coefficient of clearance volume of the second stage when applying the design value of the clearance volume.
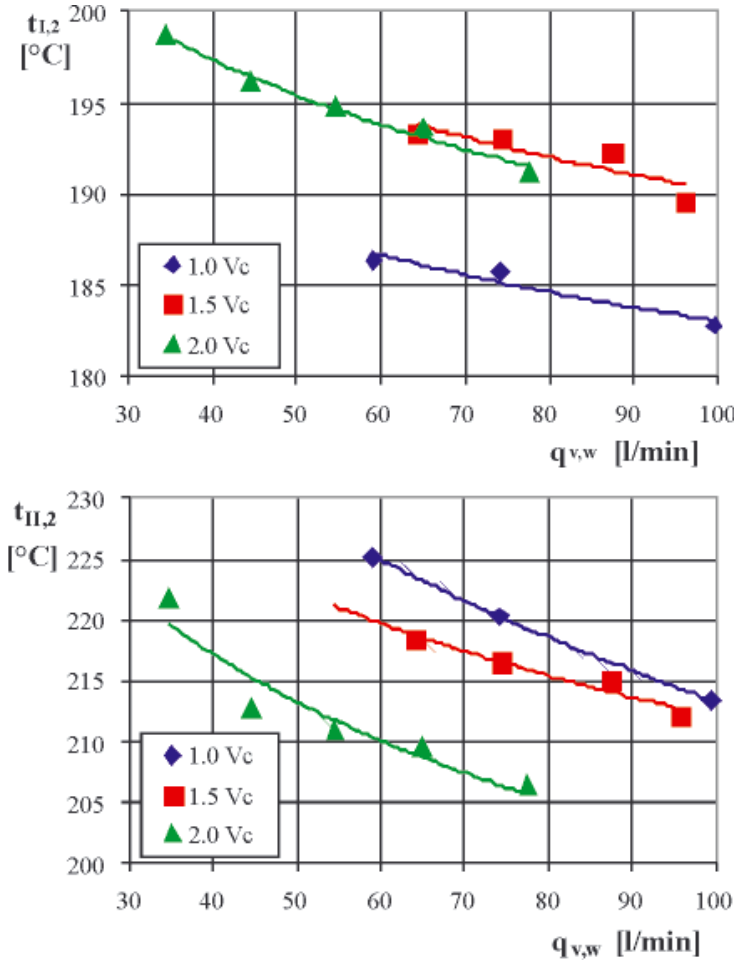

Fig. 7. The comparison of the runs of air temperature in the compression chambers of the first and second stages in function of the volumetric flow rate of the cooling water $q_{v w}$ for three values of the clearance volume $V_{C}$ at the maintained values: $t_{o}=15^{\circ} \mathrm{C}$ and $N=1500 \mathrm{rpm}$
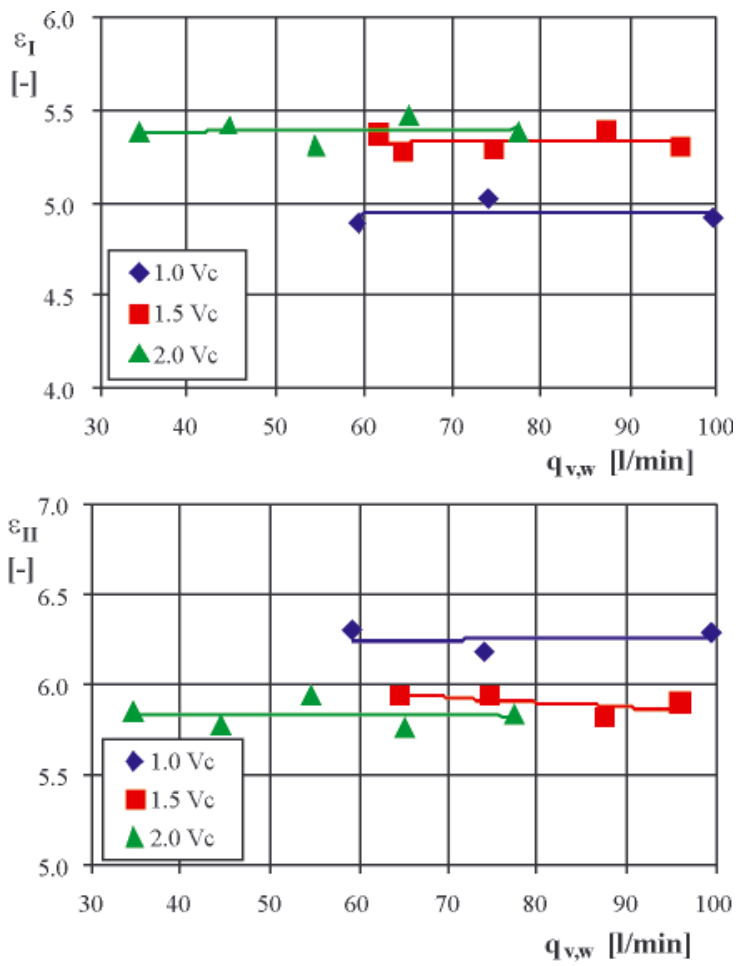

Fig. 8. The comparison of the runs of pressure ratio of the first and second stages in function of the volumetric flow rate of the cooling water $q_{v,}$ for three values of the clearance volume $V_{C}$, at the maintained values: $t_{o}=15{ }^{\circ} \mathrm{C}$ and $N=1500 \mathrm{rpm}$ 
a)

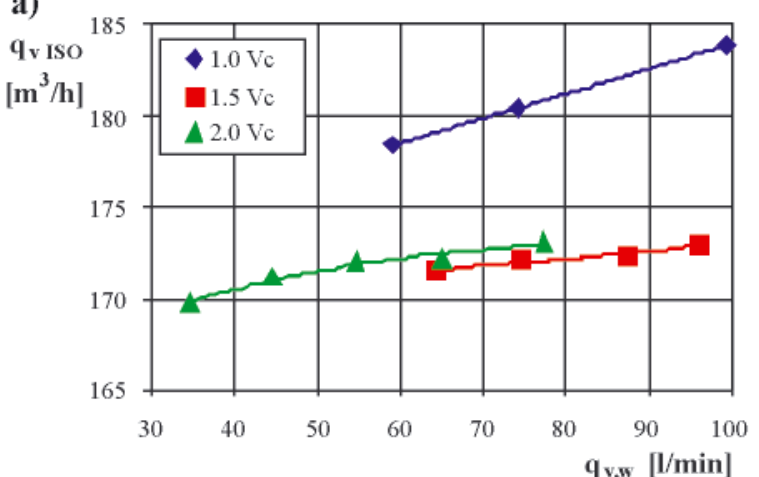

b)

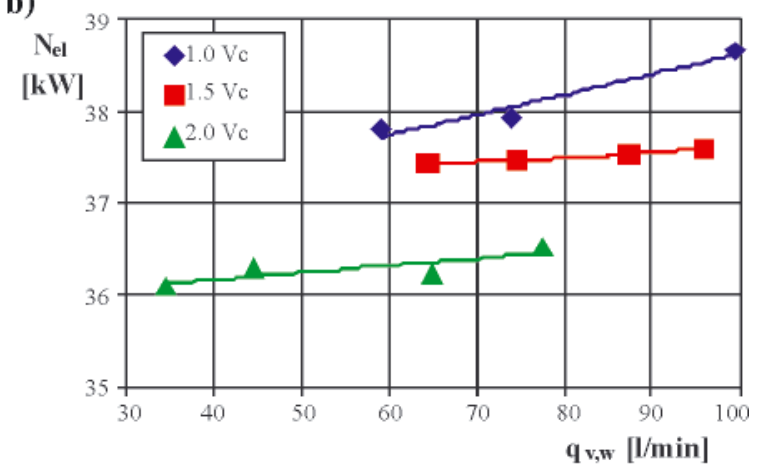

Fig. 9. The comparison of the runs of the compressed air volumetric flow rate (a) and the electric power (b) measured at the electric motor terminals in function of the volumetric flow rate of the cooling water $q_{v, w}$ for three values of the clearance volume $V_{C}$, at the maintained values: $t_{o}=15^{\circ} \mathrm{C}$ and $N=1500 \mathrm{rpm}$
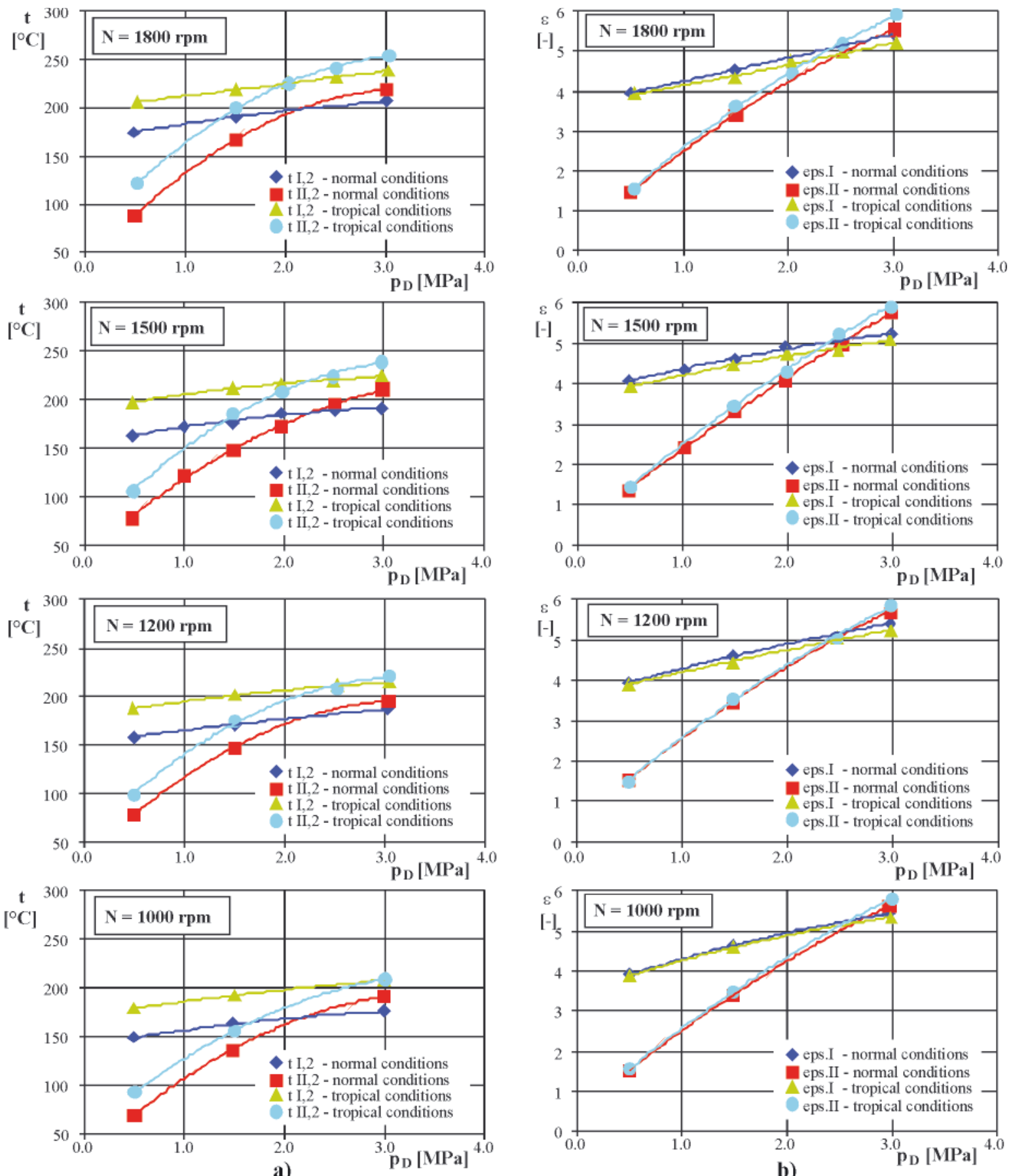

b)

Fig. 10. The comparison of the runs of air temperature in the compression chambers of the first and second stages (a) and the pressure ratio (b) in function of discharge pressure for normal conditions: $t_{o}=15{ }^{\circ} \mathrm{C}$, tropical conditions: $t_{o}=45^{\circ} \mathrm{C}$, and four crankshaft speed values: $N=1800,1500,1200$ and 1000 rpm, at the maintained constant value of the volumetric cooling-water flow rate $q_{v, w}=140 \mathrm{l} / \mathrm{min}$ 
As a result of increasing the clearance volume of the second stage a drop in the operating parameters such as the volumetric flow rate or compressing power (Fig. 9), must be expected. In the case of extreme values of the clearance volumes $\left(\mathrm{V}_{\mathrm{C}}\right.$ and $2.0 \mathrm{~V}_{\mathrm{C}}$ ) the difference between the clearance volumes and the electric power demand amounts to $\Delta \mathrm{q}_{\mathrm{v}}=4 \%, \Delta \mathrm{N}_{\mathrm{el}}=4.5 \%$, respectively. The application of a greater clearance volume enables to obtain a less varied pressure ratio distribution (Fig. 8) that consequently contributes to a reduction of differences in the temperatures between the first and the second stages $\left(\Delta \mathrm{t}=22^{\circ} \mathrm{C}\right)$ and to the simultaneous reduction of the volumetric flow rate of the cooling water to the value of $\mathrm{q}_{\mathrm{v}, \mathrm{w}}=35 \mathrm{l} / \mathrm{min}$ (Fig. 7). The lower amount of cooling water ensures a better index of cooling water per unit of compressed air, not exceeding the admissible temperature in any of the stages.

The next stage [phase] of the research consisted in performing measurements in tropical conditions. For the evaluation of the compressor cooling system under tropical conditions the author used the runs of the discharge temperatures in function of discharge pressure for each of the compressing stages and of the distribution of pressure ratios in function of discharge pressure. The obtained results were subjected to the analysis for four crankshaft speeds: 1000; 1200; 1500 and $1800 \mathrm{rpm}$, which is presented in Fig. 10 in the form of graphs.

Basing on the runs of the discharge temperatures in function of discharge pressure one can observe higher values for tropical conditions in the whole adjustable range. A disadvantageous fact is the excess of the admissible temperature in the second stage at the crankshaft speed of 1800 and $1500 \mathrm{rpm}$, which exceeds $250{ }^{\circ} \mathrm{C}$ at the speed of $\mathrm{N}=1800 \mathrm{rpm}$. Moving towards lower speeds one can observe a drop in the temperature and the even more important fact that the discharge temperature of the first and second stages levels and does not exceed $210^{\circ} \mathrm{C}$. Such a great drop in the discharge temperature for each of the stages results from the drop of the temperature at the suction to the second stage and a growth in the heat exchange rate through the cylinder walls as a result of the lower value of the cooling-water temperature in the inter-cooler.

Subsequently, analyzing the graphs showing the runs of pressure ratio in function of discharge pressure for the tropical conditions one can observe a greater pressure ratio diversification as compared to normal conditions. The reason for this is the reduction of the heat-up volumetric coefficient of the first stage, particularly at the speed $\mathrm{N}=1800 \mathrm{rpm}$. The relative difference between the pressure ratios at this speed is $\delta \varepsilon=15 \%$ and for $\mathrm{N}=1000 \mathrm{rpm}$ this difference is twice lower and amounts to $\delta \varepsilon=8 \%$.

The concluding element of the research are the measurements of the pressure in function of crankshaft angle. On the basis of the obtained results indicator diagrams were drawn for two crankshaft speeds $\mathrm{N}=1800$ and $1500 \mathrm{rpm}$ and two values of the discharge pressure $\mathrm{p}_{\mathrm{D}}=1.5$ and $3.0 \mathrm{MPa}$. The diagrams were drawn in the form of a run of pressure in the cylinder in function of volume. The obtained diagrams are presented in Fig. 11 through 18 . On each of the diagrams the thermodynamic processes responsible for the process of compression and expansion of gas inside the cylinder, are depicted. The reference point for the curves describing the processes occurring in the compressor are the isentropic $(n=\kappa)$ and isothermal $(n=1)$ processes. The reflecting of the process along the curve of compression and expansion carries an error resulting from the application of approximation consisting in describing the polytropic exponent of the whole process by a single value based on the below presented equation of polytropic process:

$$
\mathrm{p}_{1} \mathrm{~V}_{1}^{\mathrm{n}}=\mathrm{p}_{2} \mathrm{~V}_{2}^{\mathrm{n}}=\mathrm{const}
$$

The obtained results are first presented for the first stage (Fig. $11 \div 14$ ). Fig. 15 through 18 show the results for the second stage with taking into account the same discharge pressures and crankshaft speeds as for the first stage.

Analyzing the compression process in the first stage one can observe very good conformity of the line of actual process with the polytropic process of the exponent $\mathrm{n}$ in the range $\mathrm{n}=1.4 \div 1.44$. Such high values of the polytropic exponents result from a low intensity of the heat transfer through the

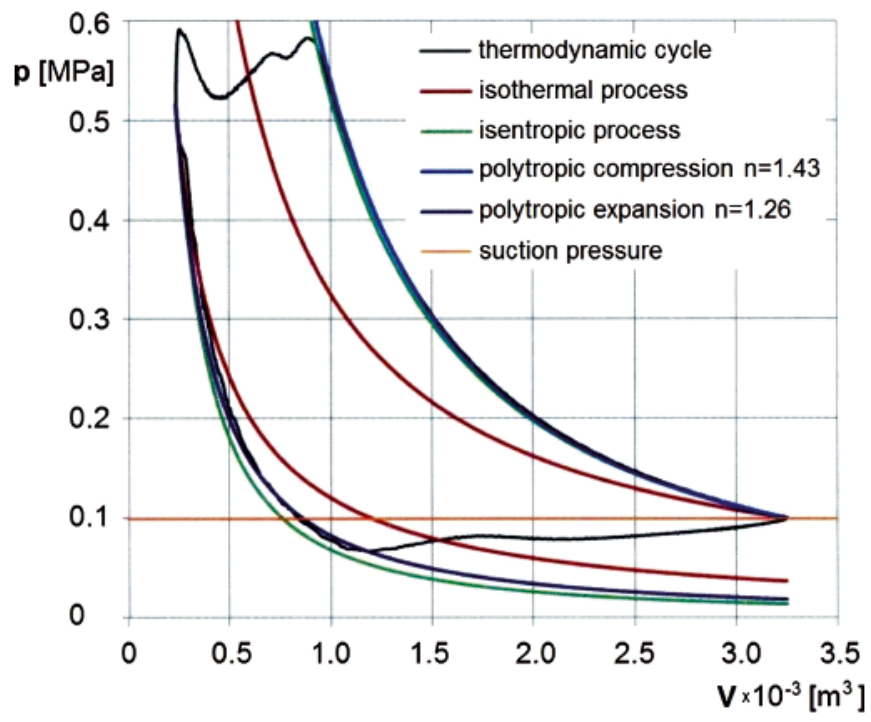

Fig. 11. Indicator diagram for the first stage, $N=1500 \mathrm{rpm}, p_{D}=1.5 \mathrm{MPa}$

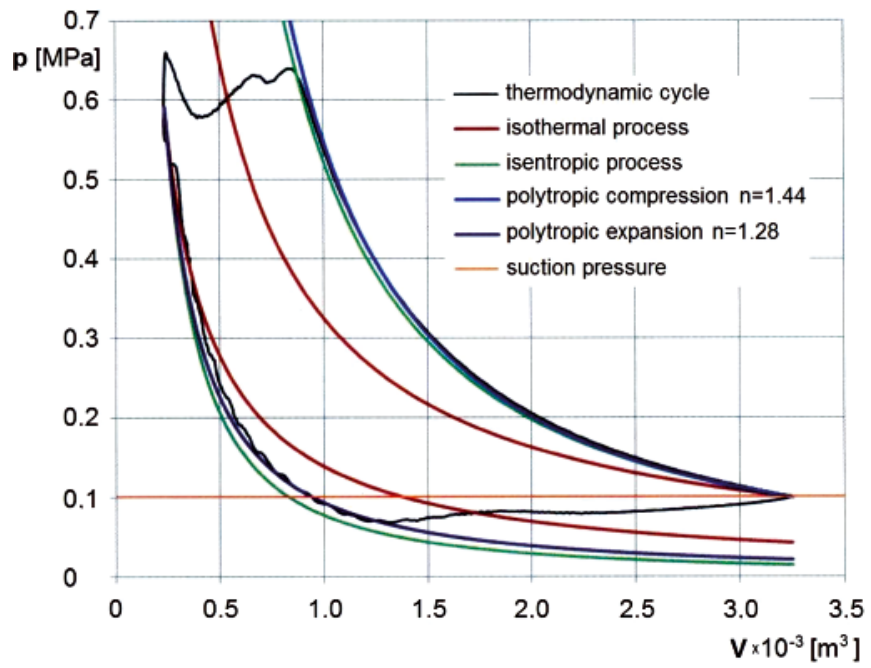

Fig. 12. Indicator diagram for the first stage, $N=1500 \mathrm{rpm}, p_{D}=3.0 \mathrm{MPa}$

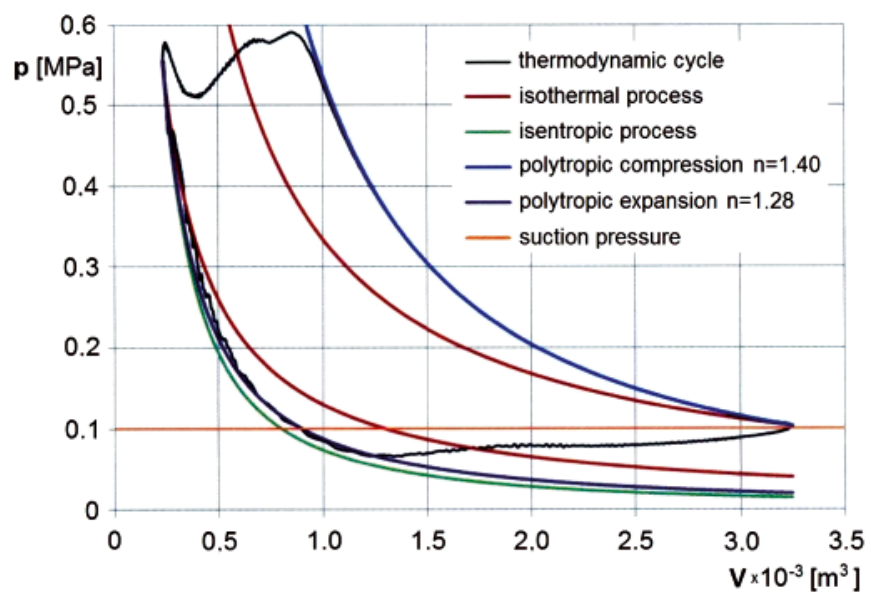

Fig. 13. Indicator diagram for the first stage, $N=1800 \mathrm{rpm}, p_{D}=1.5 \mathrm{MPa}$ 


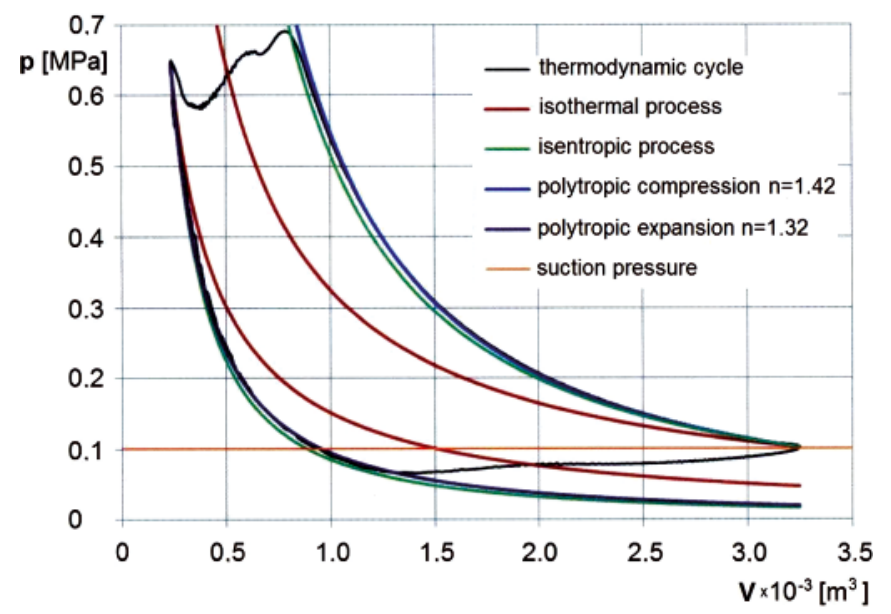

Fig. 14. Indicator diagram for the first stage, $N=1800 \mathrm{rpm}, p_{D}=3.0 \mathrm{MPa}$

cylinder walls, which results mainly from the relationship between the cylinder volume and the area of heat exchange (area of the cylinder walls).

The process of expansion takes place at lower values of the polytropic exponents within the range of $n=1.26 \div 1.32$.

A much more advantageous, in terms of the polytropic exponents, is the second stage. In Fig. $15 \div 18$ which take into account different parameters of the compressor, are shown the results obtained by the author, namely the range of the polytropic exponent $\mathrm{n}=1.24 \div 1.31$. The obtained value results from a more advantageous relation ratio of the cylinder volume and the area of the cylinder walls. Hence, the

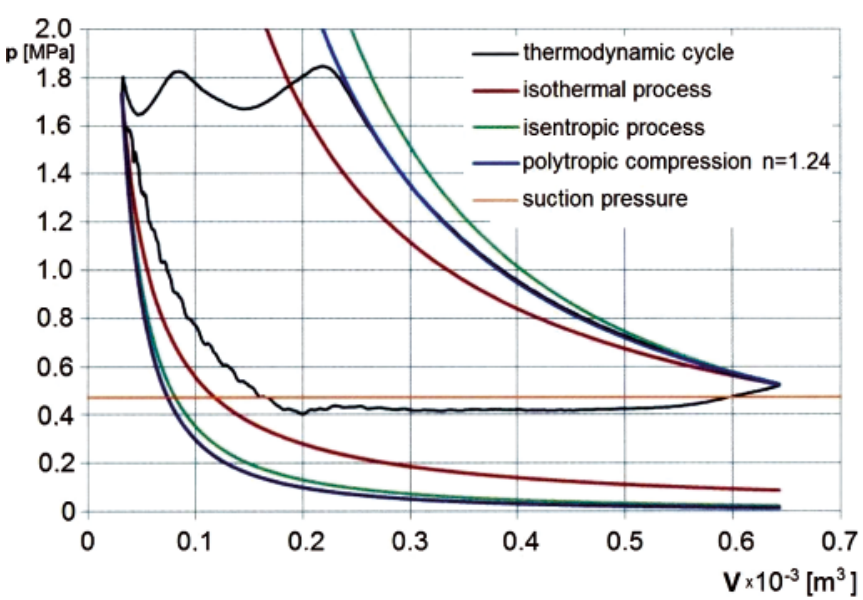

Fig. 15. Indicator diagram for the second stage, $N=1500 \mathrm{rpm}, p_{D}=1.5 \mathrm{MPa}$

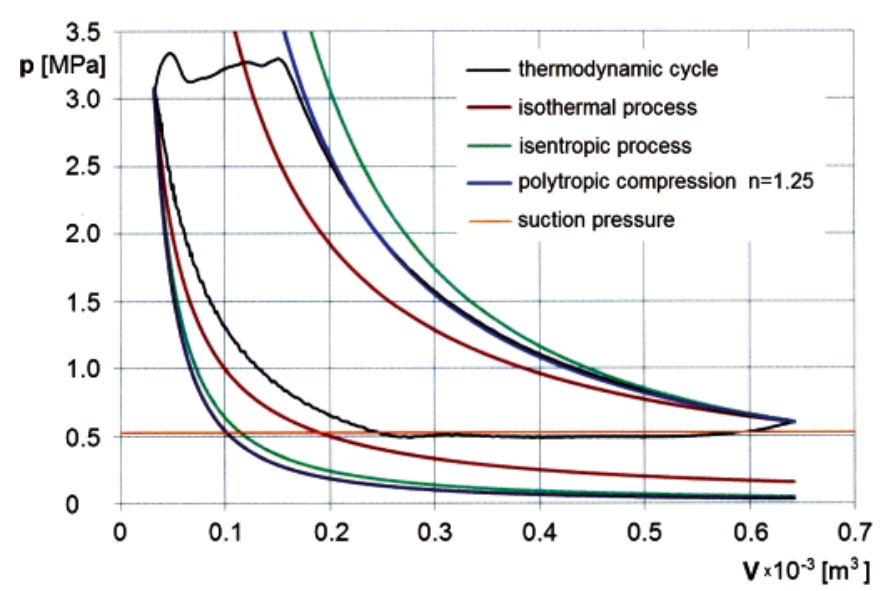

Fig. 16. Indicator diagram for the second stage, $N=1500 \mathrm{rpm}, p_{D}=3.0 \mathrm{MPa}$

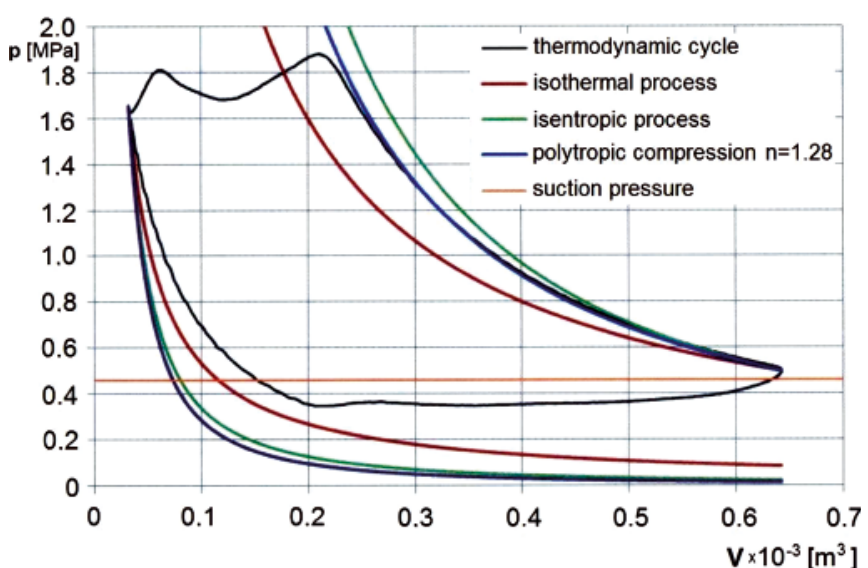

Fig. 17. Indicator diagram for the second stage, $N=1800 \mathrm{rpm}, p_{D}=1.5 \mathrm{MPa}$

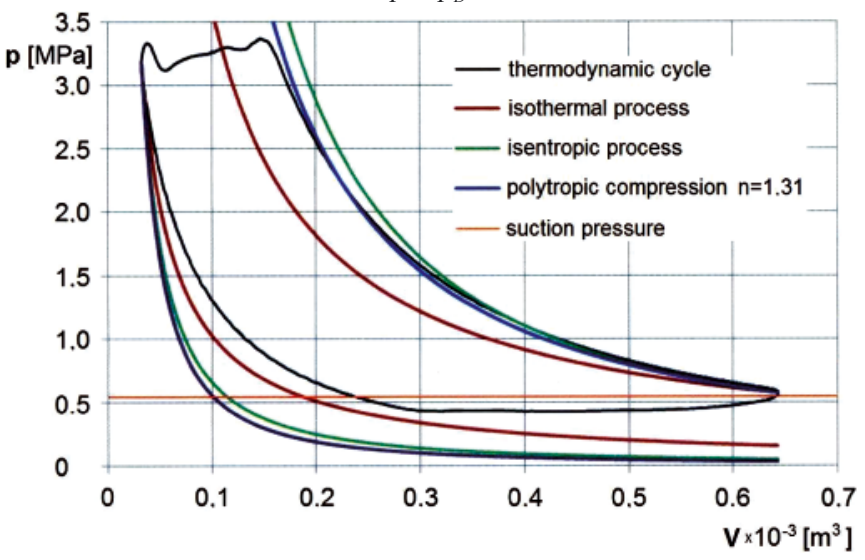

Fig. 18. Indicator diagram for the second stage, $N=1800 \mathrm{rpm}, \mathrm{p}_{\mathrm{D}}=3.0 \mathrm{MPa}$

closer the compression process to isothermal one the greater thermodynamic efficiency of the second stage.

In the case of the second stage an uncertainty as to the determined polytropic exponents appears because the run of the pressure in function of volume confirms that the leakage from the discharge valve occurs. This is revealed in the form of a significant divergence between the lines of the actual process and the isothermal one (the actual process line is on the right of the isothermal one, which does not take place in the thermodynamic sense but only confirms occurrence of the said leakage from the discharge valve).

In order to complement the interpretation of the values of the polytropic exponents, were made calculations consisting in determining the exponents based on the average values of the thermodynamic parameters recorded during the research investigations. The parameters are temperature and pressure values in the suction and discharge chamber of each of the stages. The equation for the determination of the polytropic exponents is presented below:

$$
\mathrm{n}=\frac{1}{1-\frac{\ln \frac{\mathrm{T}_{2}}{\mathrm{~T}_{1}}}{\ln \frac{\mathrm{p}_{2}}{\mathrm{p}_{1}}}}
$$

The obtained values are shown in Fig. 19 in the form of curves representing the polytropic exponent in function of crankshaft speed. The presented results were complemented with results of the run of the polytropic exponents for tropical conditions. For both normal and tropical conditions one can observe a drop in the polytropic exponent towards lower 
crankshaft speeds. The observed trend is correct due to the approximation of the thermodynamic processes along with the decrease in the crankshaft speed to quasi-statistical processes. A more intense change of the polytropic exponent took place for the first compressing stage and the value of the polytropic exponent amounted to $\mathrm{n}=1.46$ for the highest crankshaft speed $(\mathrm{N}=1800 \mathrm{rpm})$ and $\mathrm{n}=1.39$ for the speed $\mathrm{N}=1000 \mathrm{rpm}$. As for the second stage, a drop in the value of the polytropic exponent occurred at the extreme crankshaft speed and amounted to $\Delta \mathrm{n}=0.023$.

The obtained values of the polytropic exponent for tropical conditions confirm a more advantageous heat transfer through the cylinder walls to the cooling water. There are several factors influencing the values of the exponents. The first and most important is the assumption of the temperature of the cooling water in the tropical conditions by $5^{\circ} \mathrm{C}$ lower than that at the intake. Another factor to the benefit of the tropical conditions is a higher oil temperature that lowers the surface friction losses in the piston-cylinder assembly.

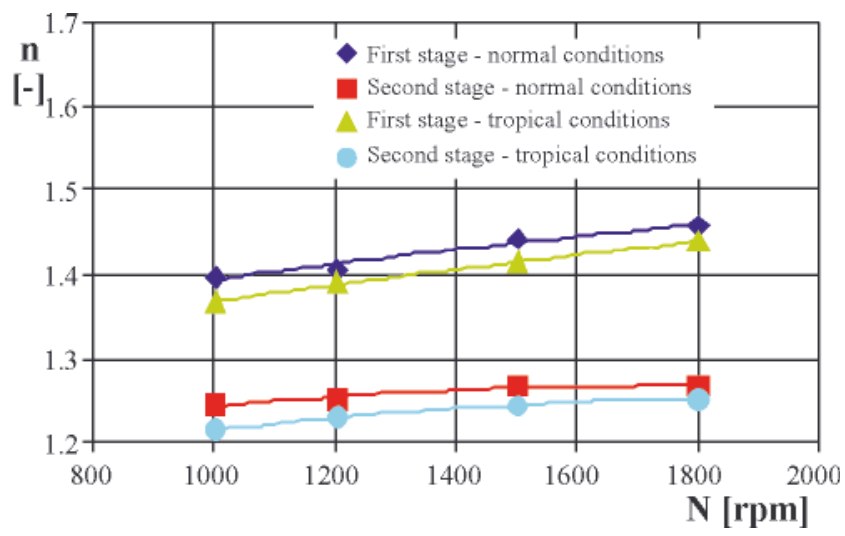

Fig. 19. The runs of the polytropic exponents in function of compressor crankshaft speed for normal and tropical ambient conditions

\section{SUMMARY AND CONCLUSIONS}

On the basis of the performed research investigations and the analysis of the obtained calculation results of the physical quantities which influence the evaluation of the compressor cooling system, the following conclusions were drawn:

- the compressor coolers reach high efficiency (in particular the inter-cooler whose lowest efficiency value amounts to $\mathrm{E}=0.88)$ at the cooling- water volumetric flow rate $\mathrm{q}_{\mathrm{v}, \mathrm{w}}=$ $30 \mathrm{l} / \mathrm{min}$;
- the system of coolers ensures sufficient cooling for the compressor at a minimum amount of water, with the flow rate of $\mathrm{q}_{\mathrm{v}, \mathrm{w}}=35 \mathrm{l} / \mathrm{min}$ for the normal ambient conditions, at the maintaining an even pressure ratio distribution between the stages.

- under the tropical ambient conditions the admissible discharge pressure in the second stage was exceeded at the crankshaft speed values: $\mathrm{N}=1500$ and $1800 \mathrm{rpm}$.

The prototype of the VC compressor, apart from the trials carried out in H. Cegielski Poznan S.A., was subjected to trials under supervision of PRS (Polish Register of Shipping) and the trials on the ferry POMERANIA. All the trials were successful. The only unfavourable effect which happened during the trials was the overheating of the concentric valve of the second stage. It was caused by an insufficient amount of cooling water supplied to the system. Eventually, upon the conclusion of the trials, Polska Żegluga Bałtycka S.A. (Polish Baltic Shipping Co - Polferries) has stated in its letter directed to H.Cegielski S.A., that the compressor fully meets the Company's expectations.

\section{BIBLIOGRAPHY}

1. Hagel R., Zakrzewski J.: Dynamic metrology (in Polish). WNT,Warszawa 1984

2. Fodemski T. et al.: Thermal measurements (in Polish). WNT, Warszawa 2001

3. Walczak J., Tyrcha J., Grzelczak M.: Elaboration of construction of series of types of special purpose piston compressors and putting it into production (in Polish). Report No. KBN 3127/ C.T07-6/2002

4. Wiśniewski S., Wiśniewski T. S.: Heat exchange (in Polish). WNT, Warszawa 2000.

\section{CONTACT WITH THE AUTHOR}

Mateusz Grzelczak, Ph.D. Faculty of Machines and Transportation Poznan University of Technology Piotrowo 3

60-965 Poznan, POLAND

e-mail: mateusz.grzelczak@put.poznan.pl 